\title{
On the Quantitative Importance of Wage Bargaining Models*
}

\author{
James S. Costain \\ Universitat Pompeu Fabra \\ January 1998
}

Correspondence address:

Department of Economics and Business

Universitat Pompeu Fabra

Ramon Trias Fargas 25-27

08005 Barcelona Spain

james.costain@econ.upf.es

*This project owes much to my dissertation committee members Michael Woodford, Steven Davis and Lars Hansen. Comments from Dale Mortensen, Daron Acemoglu, Eric Smith, and Asher Wolinsky also helped me clarify some ideas before I wrote this paper. All errors, of course, are my own. 


\section{Abstract}

Four general equilibrium search models are compared quantitatively. The baseline framework is a calibrated macroeconomic model of the US economy designed for a welfare analysis of unemployment insurance policy. The other models make three simple and natural specification changes, regarding tax incidence, monopsony power in wage determination, and the relevant threat point. These specification changes have a major impact on the equilibrium and on the welfare implications of unemployment insurance, partly because search externalities magnify the effects of wage changes. The optimal level of unemployment insurance depends strongly on whether raising benefits has a larger impact on search effort or on hiring expenditure.

JET classification: C78, J64, J65

Keywords: Wage bargaining, search, matching, unemployment insurance, tax incidence, monopsony, threat point 


\section{Introduction}

Deriving the necessary conditions that characterize the equilibrium wage is not as simple in search and matching models as it is in frictionless market clearing models. In the latter, it is assumed that if either a worker or a firm prefers not to participate in a given wage contract, that party can instantaneously, costlessly find an alternative partner. No employer, then, will ever offer to pay more or less than the prevailing wage to his employees; paying less would cause them to go elsewhere, while paying more would be, from the firm's point of view, wasteful. This indifference property yields the marginal conditions which determine the equilibrium wage.

No such indifference condition applies to the context of search, or to other contemporary models that incorporate costs of entering or exiting bilateral relationships, such as models with firm-specific human capital or firing restrictions. With costly frictions, both members of an employer-employee pair are better off within their ongoing relationship than outside it, because if their match were to separate they would again have to suffer the frictions before working with a new partner. The increment to the intertemporal welfare of the two partners that results from their match is called the match surplus. Wage determination, then, becomes a question of how much of the surplus accrues to each partner; that is, wage determination requires bilateral bargaining. While bilateral bargaining theory acquired a powerful paradigm with the contribution of Rubinstein (1982), there are still many different specifications of bargaining which are actively debated in the literature. Thus, there is not yet a unique accepted wage specification for matching models.

The purpose of this paper is to shed some quantitative light on the debate over the appropriate way of specifying wage determination, on the basis of a calibrated model of the US economy. We compare four different wage frameworks which arise naturally from small changes in the bargaining process. No claim is made that the bargaining alternatives discussed here are new; they are well known from the theoretical literature. Instead, we ask whether the various theoretical models exhibit quantitatively significant differences, and 
we find indeed that this is the case. The alternatives discussed here are all nested within the same calibrated general equilibrium economy and evaluated under the same set of parameters. The baseline model is that used in Costain (1997b) to perform a welfare analysis of unemployment insurance (UI), and our comparison across wage bargaining specifications will include implications for optimal UI.

We will discuss the following alternative specifications. First, we explore the effects of imposing payroll taxes on workers, instead of on firms, and we also note that the precise way in which taxes enter into the threat point is important. Second, we consider the impact of monopsony purchasing power which potentially arises in matching models where firms employ multiple workers, or where they also purchase capital. Third, we explore the implications of two different definitions of the match surplus, which define the threat point in the surplus calculation either in terms of the payoff associated with a strike, or the payoff associated with a quit. A fourth issue worth exploring is the effect of allowing the wage to vary with asset holdings in a concave utility model; however, we leave this for future research, as it requires a very different computational framework from that employed for the other models.

\section{The model}

Before we go on to discuss the theoretical wage bargaining issues we wish to explore, we outline the calibrated macroeconomic model within which all our wage formulations will be embedded. In our model, finitely-lived, risk averse workers smooth consumption over time by accumulating assets, choose search effort when unemployed, and suffer disutility from work. Firms hire workers, purchase capital, and pay taxes to finance worker benefits; their equity is the asset accumulated by workers. A matching function relates unemployment, hiring expenditure, and search effort to the formation of jobs; separation is exogenous. Workers receive UI payments for the first two periods of any unemployment spell, and social security benefits when retired. These aspects of 
the model are intended to capture the consumption smoothing benefits of UI together with its disincentive effects on job search and hiring. ${ }^{1}$

\subsection{The problems of the worker and the firm}

We will perform only steady state analysis in this paper, so it suffices to describe the problems of the worker and the firm without reference to any aggregate state variables. The worker chooses consumption and search intensity over time to maximize the expected present value of lifetime utility. Workers have a life of deterministic length $T+T^{R}$ periods; for the first $T$ periods of life, they are able to work, and over the last $T^{R}$ periods, they are retired. We write $I^{W} \equiv T /\left(T+T^{R}\right)$ for the fraction of individuals of working age. The problem of a worker born at time 0 is stated in Table 1 , and workers born at other times face analogous problems. ${ }^{2}$

Workers' consumption utility is given approximately by the constant relative risk aversion form $(1 / \alpha) c^{\alpha}$ where the coefficient of relative risk aversion is $1-\alpha$, with $\alpha \leq 1$. The small constant $\bar{\chi}$ is added to consumption in order to ensure bounded utility even when $c=0$. During the first $T$ periods of life, a worker will either be employed or unemployed. If unemployed, she chooses search effort $s_{t}$, incurring search disutility $D^{S} s_{t}$, where $D^{S}>0$. If employed, she experiences a fixed level of disutility $D^{W}>0$. She discounts utility over time at rate $\rho$. In practice, numerical calculation of the model requires us to restrict her choices of consumption and search to finite non-negative sets $\mathcal{C}$ and $\mathcal{S}$, both of which are assumed to include zero.

The state variables on which a worker conditions her choices of consumption and search at time $t$ are assets $a_{t}$ and employment status $\epsilon_{t}$. Five possible labor market states are relevant; $\epsilon=1$ designates employment. The first and second

\footnotetext{
${ }^{1}$ For greater detail on the model, including parameterization issues, see Costain (1997b).

${ }^{2}$ We are abusing notation somewhat to simplify the statement of the problem. Consumption $c_{t}$ and search $s_{t}$ should be written as functions of assets and employment status instead of being merely subscripted by $t$. Also, the asset dynamics equation is written in a simplified form which fails to account for the fact that our numerical procedure keeps assets constrained to a finite grid at all times.
} 
Table 1: The worker's problem

$$
\begin{aligned}
& \operatorname{Max}_{c_{t} \in \mathcal{C}} \\
& s_{t} \in \mathcal{S}
\end{aligned} \quad E_{0} \sum_{0 \leq t<T+T^{R}} e^{-\rho t}\left[\frac{1}{\alpha}\left(c_{t}+\underline{\chi}\right)^{\alpha}-D^{S} s_{t}-D^{W} \mathbf{1}_{\left\{\epsilon_{t}=1\right\}}\right]
$$

subject to:

$$
\begin{gathered}
a_{t+1}=R\left(a_{t}+w \mathbf{1}_{\left\{\epsilon_{t}=1\right\}}+b^{U} \mathbf{1}_{\left\{\epsilon_{t}=2 \vee \epsilon_{t}=3\right\}}+b^{R} \mathbf{1}_{\left\{\epsilon_{t}=5\right\}}-c_{t}\right) \quad \forall a_{t}, \epsilon_{t}, t \\
\text { where } a_{0}=0 \text { and } a_{T+T^{R}} \geq 0 \text { for all histories. }
\end{gathered}
$$

Also subject to the employment transition equations:

$$
\operatorname{pr}\left(\epsilon_{0}=1\right)=p_{0} ; \quad \epsilon_{t}=5 \text { for } t \geq T
$$

probability of unemployment at $t+1$ if employed at $t$

$$
=1-\exp (-\delta)
$$

probability of employment at $t+1$ if unemployed at $t$

$$
=1-\exp \left(-\pi s_{t}{ }^{Z}\right)
$$


periods of an unemployment spell are given by $\epsilon=2$ and $\epsilon=3$, respectively; $\epsilon=4$ refers to the third and later periods of an unemployment spell, when the worker is ineligible for UI. Finally, $\epsilon=5$ means that the worker is retired. The notation $\mathbf{1}\{\}$ appearing in the worker's problem is an indicator function which equals 1 when its argument is true and zero otherwise. Workers receive wage $w$ when employed, UI benefit $b^{U}$ over the first two periods of any unemployment spell, and social security benefit $b^{R}$ when retired. Allowing for interest factor $R$ between any two periods, the law of motion for assets is:

$$
a_{t+1}=R\left(a_{t}+w \mathbf{1}_{\left\{\epsilon_{t}=1\right\}}+b^{U} \mathbf{1}_{\left\{\epsilon_{t}=2 \vee \epsilon_{t}=3\right\}}+b^{R} \mathbf{1}_{\left\{\epsilon_{t}=5\right\}}-c_{t}\right)
$$

The labor status process begins with a positive probability $p_{0}$ of starting life employed. ${ }^{3}$ Employed workers not yet ready to retire face an exogenous probability $1-\exp (-\delta)$ of becoming unemployed each period. The probability that an unemployed worker becomes employed is $1-\exp \left(-\pi s^{Z}\right)$ if search effort $s$ is chosen, which is approximately $\pi s^{Z}$ if $s$ is sufficiently small. The coefficient $\pi$ is an endogenous variable which depends in equilibrium on the unemployment rate and on the level of recruitment by firms, while $Z \in[0,1]$ is an exogenous constant.

The firm's problem, unlike that of the worker, is an infinite horizon, deterministic problem, for we assume that firms are large enough to ignore uncertainty about the arrival of individual workers. Firms act in the interest of their shareholders by maximizing the present value of profits. They hire labor $n_{t}$ and purchase capital $k_{t}$, producing gross output $A n_{t}{ }^{\gamma} k_{t}{ }^{1-\gamma}$, and the net revenue above their costs is paid out as dividends. Each unit of investment expenditure $i_{t}$ creates one unit of new capital, while hiring expenditure $h_{t}$ leads to the arrival of new employees at rate $q h_{t}$, where $q$ is an endogenous coefficient related in equilibrium to the search and hiring effort of all workers

\footnotetext{
${ }^{3}$ This assumption is made for analytical convenience, because we can then assume that some jobs of retiring workers are inherited by new workers, and thus pick $p_{0}$ in such a way that the firm's problem can be solved without taking into account the age distribution of its employees.
} 
and firms. The fraction of capital which remains after one period's depreciation is $\exp \left(-\delta_{k}\right)$, and likewise the fraction of workers who are still employed at the firm after a period is $\exp (-\delta)$.

For each worker, each period, firms must pay a tax $\tau$ and a wage $w\left(n_{t}, k_{t}\right)$ which we write in general as a function of the firm's labor and capital stocks. This paper addresses the quantitative effects of several versions of the wage $w\left(n_{t}, k_{t}\right)$ which arise from a variety of sensible specifications of the bargaining game. For all wage specifications, we can state the firm's problem in terms of its value function $V\left(n_{t}, k_{t}\right)$ as:

$$
\begin{gathered}
V\left(n_{t}, k_{t}\right)=\operatorname{Max}_{h_{t}, i_{t}}\left\{A n_{t}^{\gamma} k_{t}{ }^{1-\gamma}-w\left(n_{t}, k_{t}\right) n_{t}-\tau n_{t}-h_{t}-i_{t}+\frac{1}{R} V\left(n_{t+1}, k_{t+1}\right)\right\} \\
\text { s.t. } n_{t+1}=q h_{t}+\exp (-\delta) n_{t} \\
\text { and } \quad k_{t+1}=i_{t}+\exp \left(-\delta_{k}\right) k_{t}
\end{gathered}
$$

This problem yields the following pair of steady state Euler equations:

$$
\begin{gathered}
R-\exp \left(-\delta_{k}\right)=A(1-\gamma) n_{t}^{\gamma} k_{t}{ }^{-\gamma}-n_{t} \frac{\partial}{\partial k_{t}} w\left(n_{t}, k_{t}\right) \\
R-\exp (-\delta)=q\left(A \gamma n_{t}{ }^{\gamma-1} k_{t}{ }^{1-\gamma}-w\left(n_{t}, k_{t}\right)-\tau-n_{t} \frac{\partial}{\partial n_{t}} w\left(n_{t}, k_{t}\right)\right)
\end{gathered}
$$

This formulation of the problem embodies constant returns to scale under all versions of wage bargaining that we will study below - that is, the equilibrium size of firms is indeterminate. Hence we will use the notation $n_{t}$ to refer to the economy-wide total of employment, rather than employment at a specific firm; we will use $k_{t}, h_{t}$, and $i_{t}$ analogously.

\subsection{Aggregate consistency and solution algorithm}

Aggregate consistency between our descriptions of the problems of the worker and the firm imposes some additional necessary conditions on our equilibium. First, we require that the government follow a balanced budget at all times, equating total taxes to expenditure on UI and social security:

$$
n \tau=I^{W} u^{U I} b^{U}+\left(I-I^{W}\right) b^{R}
$$


The variable $u^{U I}$ represents the fraction of workers who are currently in the first or second period of an unemployment spell, and who are thus eligible for UI benefits. We use the notation $\phi(a, \epsilon, t)$ to refer to the number of workers of age $t$ with asset holdings $a$ and employment status $\epsilon$. We normalize the distribution so that the frequencies sum to the total number of workers $I$ :

$$
\sum_{a, \epsilon, t} \phi(a, \epsilon, t)=I
$$

Using this notation, the goods market clearing condition is

$$
A n^{\gamma} k^{1-\gamma}-i-h=\sum_{a, \epsilon, t} c(a, \epsilon, t) \phi(a, \epsilon, t)
$$

The asset market clearing condition, which equates total interest earnings on workers' assets to total dividends on equity, can be written as:

$$
\begin{gathered}
(R-1) \sum_{a, \epsilon, t} \phi(a, \epsilon, t)\left[a+w \mathbf{1}_{\{\epsilon=1\}}+b^{U} \mathbf{1}_{\{\epsilon=2 \vee \epsilon=3\}}+b^{R} \mathbf{1}_{\{\epsilon=5\}}-c(a, \epsilon, t)\right] \\
=A n^{\gamma} k^{1-\gamma}-w n-\tau n-h-i
\end{gathered}
$$

The relevant rates of unemployment in our economy can be defined as

$$
u^{U I}=\sum_{a, \epsilon, t} \mathbf{1}_{\{\epsilon=2 \vee \epsilon=3\}} \phi(a, \epsilon, t)
$$

and

$$
u^{T O T}=\sum_{a, \epsilon, t} \mathbf{1}_{\{\epsilon=2 \vee \epsilon=3 \vee \epsilon=4\}} \phi(a, \epsilon, t)
$$

Equality of labor market stocks requires that

$$
I^{W}\left(1-u^{T O T}\right)=n
$$

Consistency of separation flows is imposed by assuming that workers and firms become separated with constant probability $(1-\exp (-\delta))$; this means implicitly that fraction $\exp (-\delta)$ of the jobs held by retiring workers are inherited by newborn workers in the next period, which greatly simplifies the 
firm's problem. For consistency of matching flows, we define the matching coefficients as follows:

$$
\begin{gathered}
\pi \equiv \mu h^{\xi}\left(I^{W} u^{T O T}\right)^{-\xi} \\
q \equiv \frac{1}{h} \sum_{a, \epsilon, t} \phi(a, \epsilon, t)\left(1-\exp \left(-\pi s(a, \epsilon, t)^{Z}\right)\right)
\end{gathered}
$$

We assume that the exogenous parameters here satisfy $\mu>0$ and $\xi \in(0,1)$. With these definitions, we have total matches formed per period equal to

$$
q h=\sum_{a, \epsilon, t} \phi(a, \epsilon, t)\left(1-\exp \left(-\pi s(a, \epsilon, t)^{Z}\right)\right)=(1-\exp (-\delta)) n
$$

For this matching function, if all workers pick the same level of search effort $\bar{s}$, and if $\pi \bar{s}^{Z}$ is small, then we have:

$$
\sum_{a, \epsilon, t} \phi(a, \epsilon, t)\left(1-\exp \left(-\pi s(a, \epsilon, t)^{Z}\right)\right) \approx \mu h^{\xi}\left(I^{W} u\right)^{1-\xi} \bar{s}^{Z}
$$

This approximation shows that the matching function has roughly constant returns to scale in hiring and unemployment, and is also an increasing, concave function of workers' search activity.

The model just described must be solved numerically, because with the utility function we are using, no analytical solution is available. For any policy parameters $b^{U}$ and $b^{R}$, our solution method involves finding a fixed point in three variables: the interest factor $R$, the matching coefficient $\pi$, and the wage $w$. Guessing any values for $R, \pi$, and $w$, together with the given $b^{U}$ and $b^{R}$, gives the information needed to solve the individual's problem by backwards induction. The results of the worker's problem then give us all the information we need to impose the necessary conditions of the firm's problem, together with aggregate consistency conditions. Finally, we use equations (6) and (10) to update $R$ and $\pi$, respectively, and we update $w$ using one of the four wage equations which will be explained in the following sections of this paper. This algorithm is outlined in Table 2 . 
Table 2: The algorithm

0. Pick policy parameters $b^{U}, b^{R}$.

1. Make initial guesses of $R, \pi$, and $w$.

2. Given $R, \pi, w, b^{U}$, and $b^{R}$, solve the individual's problem by backwards induction.

3. From the worker's policy functions, calculate the steady state distribution of asset holdings and employment status by age.

4. From workers' steady state behavior, calculate $n, u^{T O T}, u^{U I}, \tau$, and average consumption $\bar{c}$.

5. Use the firm's Euler equations and laws of motion (1)-(2), to calculate $k, q$, $h$, and $i$.

6. Calculate new values for $R$ and $\pi$ from equations (6) and (10), and also the wage from one of the versions of the wage equation derived in Sections $3,4,5$, and 6 .

7. If guessed and predicted values of $R, \pi$, and $w$ are sufficiently close, equilibrium has been found. If not, return to step 2 . 


\section{The baseline simulation}

\subsection{Wage equation and parameterization}

The baseline model is calculated using a wage bargaining specification we will call the "strike threat" wage. In this formulation, as we will see in Section 6 below, we can ignore intertemporal considerations and instead assume that the wage splits the surplus resulting from work at any given instant. By this surplus, we mean the difference between the instantaneous payoff due to work and that due to non-work, in other words, a strike. This surplus is calculated under the assumption that tax payments are due regardless of whether work occurs, and the firm is the party that pays the tax. We assume that the firm takes as given the wage that will result from the bargaining game, so that the terms $\frac{\partial}{\partial k} w(n, k)$ and $\frac{\partial}{\partial n} w(n, k)$ appearing in equations (1)-(2) are both zero. We also ignore variation in the marginal utility of consumption across workers. We use the notation $M U \equiv(1 / \alpha)(\bar{c}+\bar{\chi})^{\alpha}$ to represent the marginal utility associated with the average level of consumption cin the economy; $M P L \equiv$ $A \gamma n^{\gamma-1} k^{1-\gamma}$ denotes the marginal product of labor.

Under these assumptions, the instantaneous difference in joint payoffs between working and striking is $M P L * M U-D^{W}$, since working produces the marginal product of labor but also causes the worker to suffer disutility. The marginal utility $M U$ appears here in order to enable us to add a quantity denominated in goods units to one denominated in terms of utility. The part of instantaneous surplus which accrues to the worker is $w * M U-D^{W}$; hence imposing bargaining share $\beta$ for the worker gives the following wage equation:

$$
w * M U-D^{W}=\beta\left(M P L * M U-D^{W}\right)
$$

or equivalently

$$
w=\beta M P L+(1-\beta) D^{W} / M U
$$

The baseline parameterization is given in Table 3. The simulation is carried out under benefit levels $b^{U}=b^{R}=0.33$, which in equilibrium implies a replacement ratio of roughly $43 \%$, similar to that in the U.S. ${ }^{4}$

\footnotetext{
${ }^{4}$ Engen and Gruber (1995) calculate that the U.S. replacement ratio is $44 \%$.
} 
Table 3: Baseline parameters

\begin{tabular}{|c|c|c|c|c|c|}
\hline \multirow{8}{*}{ Preferences } & $T$ & 180 & Matching technology & $I$ & 1 \\
\hline & $T^{R}$ & 60 & & $\beta$ & 0.5 \\
\hline & $\alpha$ & 0 & & $\delta$ & 0.04 \\
\hline & $\rho$ & 0.015 & & $\mu$ & 2.2 \\
\hline & $D^{W}$ & 0.78 & & $\xi$ & 0.55 \\
\hline & $D^{S}$ & 0.2 & & & \\
\hline & $Z$ & 0.4 & Computational parameters & $\chi$ & $1 / 12$ \\
\hline & & & & $\underline{\chi}$ & $1 / 1200$ \\
\hline \multirow[t]{4}{*}{ Production technology } & A & 0.63 & & $-A_{\min }$ & $-24 \chi$ \\
\hline & $\gamma$ & 0.67 & & $A_{\max }$ & $400 \chi$ \\
\hline & $\delta_{k}$ & 0.025 & & $c_{\max }$ & $40 \chi$ \\
\hline & & & & $\sigma_{\min }$ & -4 \\
\hline \multirow[t]{2}{*}{ Policies } & $b^{U}$ & 0.33 & & $\sigma$ & 0.5 \\
\hline & $b^{R}$ & 0.33 & & $\sigma_{\max }$ & 4 \\
\hline
\end{tabular}

To set our remaining parameters, we begin with a normalization of $I \equiv 1$, so that quantities are expressed in per capita terms, and we set the time period equal to a quarter, so that $T \equiv 180$ and $T^{R} \equiv 60$ are reasonable. The capital depreciation rate is set at $\delta^{k} \equiv 0.025$ per quarter, and the separation rate for job matches is chosen as $\delta \equiv 0.04$, a compromise between the low separation rates of prime age white males and the much higher rates of younger and minority workers. The technological parameters $A \equiv 0.63$ and $\gamma \equiv 0.67$ are chosen to make the firm's behavior consistent with a share of labor income equal to $65 \%$ of output and a level of hiring expenditure equal to $1 \%$ of output, while simultaneously normalizing output to approximately one.

We impose an equal bargaining power specification, $\beta \equiv 0.5$. The quarterly utility discount rate is $\rho \equiv 0.015$, and the consumption utility function is logarithmic, so $\alpha \equiv 0$. Given our wage equation (14), it can be shown that obtaining labor's share equal to $65 \%$ requires setting work disutility equal to $D^{W} \equiv 0.78$. The elasticity of the matching function with respect to hiring, following Blanchard and Diamond (1989), is $\xi \equiv 0.55$. The final normalization of the model involves setting the coefficient on the matching rate equal to 
$\mu \equiv 2.2$; this amounts to picking the units of search intensity, and is intended to yield an equilibrium level of search intensity roughly equal to one.

The final parameters which must be chosen are $D^{S}$ and $Z$, which are a level parameter and an elasticity parameter relating search effort to the probability of job finding. These two parameters are chosen to match four types of observations. First, they must imply a reasonable level of unemployment; we target $u=0.06$. Also, from Meyer (1990), we find that the probability of job finding should rise from 0.5 in the penultimate quarter of UI eligibility to roughly 0.7 in the last quarter of eligibility, as workers search harder in anticipation of the expiration of their benefits. Third, we learn from Solon (1985) and Meyer (1995) that a one percent increase in the replacement ratio should lead to a rise of 0.0005 in the level of unemployment. Finally, our parameter choices should lead to a fall in consumption of approximately $7 \%$ when job loss occurs, as documented in Gruber (1994). The parameters chosen are $D^{S} \equiv 0.2$ and $Z \equiv 0.4$; the calculations on which this and other parameter choices are based are described in detail in Costain (1997b).

\subsection{Baseline results}

Observations relating to the production side of the model are quite easy to match, since that part of the model is overidentified by only one equation. In our baseline equilibrium, which appears in Tables 4 and 5 as the $b^{U}=$ 0.33 case, labor's share of output (value added) is $65.72 \%$, gross investment is $20.45 \%$ of output, and recruitment expenditures are $1.74 \%$ of output. Note that recruitment is defined as an intermediate input, so it is subtracted off gross output to define value added. The baseline interest rate is $1.582 \%$, and the capital stock is 8.2838 quarters of output.

Unemployment in our baseline is somewhat higher than we targeted, at $7.647 \%$. Job loss is associated, on average, with a $3.497 \%$ drop in consumption. Raising the UI benefit from 0.1 to 0.6 almost doubles the unemployment rate, from $5.877 \%$ to $10.483 \%$. The fall in gross output is cushioned by a large decrease in hiring expenditure, so value added falls by only $2.772 \%$ of its baseline. 


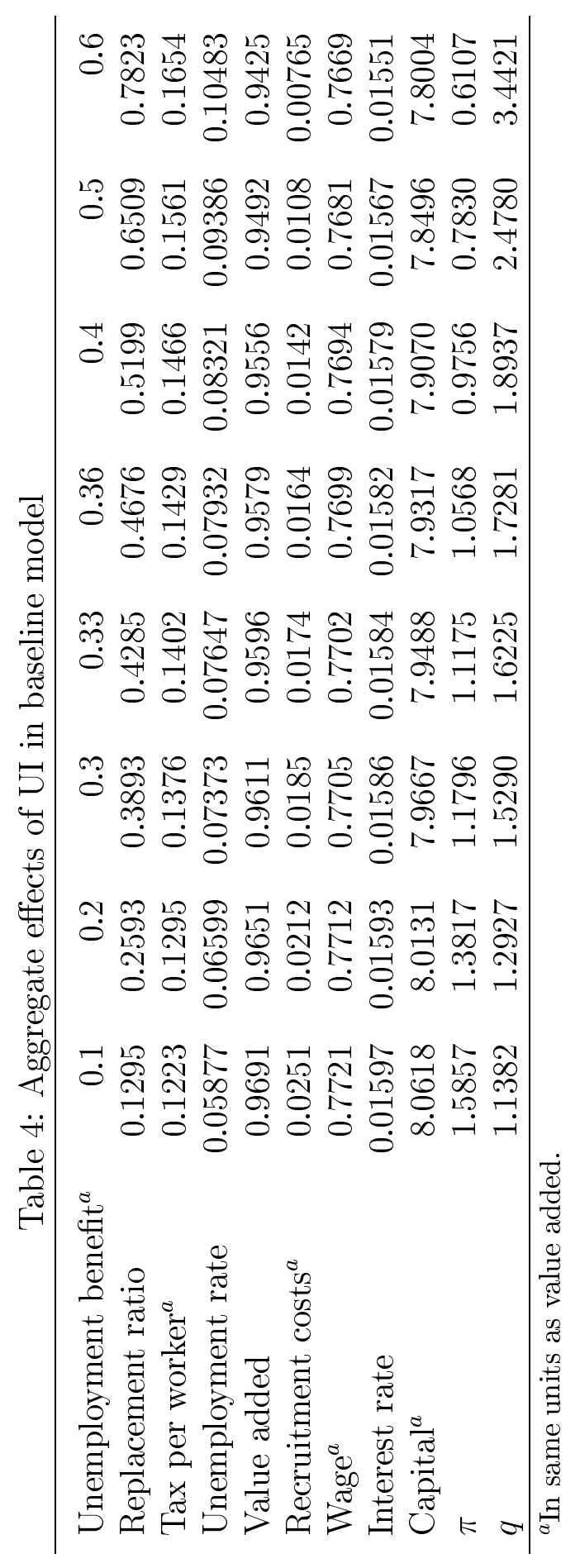




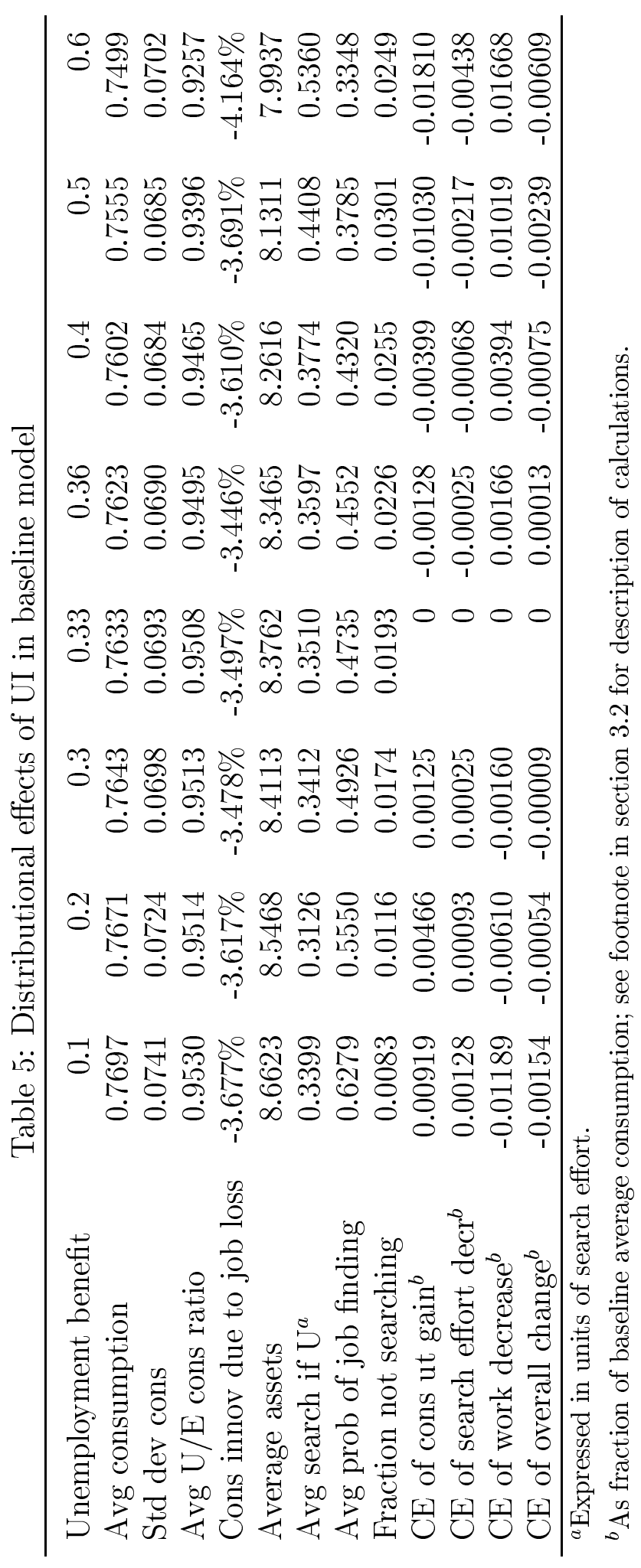


At the baseline UI level of $b^{U}=0.33$, the certainty equivalent of consumption can be calculated as $0.9958 \%$ of baseline average consumption. ${ }^{5}$ Table 5 shows how welfare varies with UI, equating the changes in the three components of utility to changes in the certainty equivalent of consumption, which is then expressed as a fraction of baseline average consumption. The utility gain of 0.00919 shown in the first column, for consumption utility, means that the certainty equivalent of consumption utility is raised by $0.919 \%$ of baseline average consumption, when the UI payment is lowered from 0.33 to $0.1 .^{6}$ Similarly, lowering UI from 0.33 to 0.1 lowers search disutility by an amount equal to a $0.128 \%$ rise in the certainty equivalent of consumption, and also raises work disutility by an amount equal to a $1.189 \%$ fall in the certainty equivalent of consumption, where both these changes are stated as a percentage of baseline average consumption. Overall, the optimal level of UI benefits in this model is approximately 0.36 , which represents a replacement ratio of $46.76 \%$. Raising UI from 0.1 to 0.36 leads to an improvement in overall utility equivalent to a rise of $0.154 \%+0.0013 \%=0.167 \%$ in the certainty equivalent of consumption, as a fraction of baseline average consumption.

There are two main conclusions to be drawn about the effects of UI in this model. First, in spite of the fairly high optimal replacement ratio in this simulation, consumption smoothing benefits per se are small. This can be seen by noting that the certainty equivalent of the loss of consumption utility, $-0.919 \%$, which occurs when UI is raised from 0.1 to 0.33 , is quite close to the corresponding percentage change in average consumption, which is $(0.7633-0.7697) / 0.7633=-0.838 \%$. That is, the utility impact of the change in the consumption distribution is well proxied by the change in average

\footnotetext{
${ }^{5}$ Let average consumption utility at the baseline level of UI be $v$; note that this does not include search or work disutility. Then the certainty equivalent $e$ is the level of consumption satisfying $(1 / \alpha)(e+\bar{\chi})^{\alpha}=v$. Let $\bar{c}$ be baseline average consumption. Then $e=0.9958 \bar{c}$, implying little scope for further improvements in utility from consumption smoothing.

${ }^{6}$ Continuing the notation from the previous footnote, let the certainty equivalent of consumption when $b^{U}=0.1$ be $e_{0.1}$. Then $\left(e_{0.1}-e\right) / \bar{c}=0.00919$. Also, let $d_{0.1}$ and $d_{0.33}$ be the levels of search disutility when $b^{U}$ is 0.1 and 0.33 . Let $\hat{e}$ satisfy $(1 / \alpha)(\hat{e}+\bar{\chi})^{\alpha}=v+d_{0.33}-d_{0.1}$. Then $(\hat{e}-e) / \bar{c}=0.00128$.
} 
consumption, without considering its variability. The fact that the consumption innovation due to job loss eventually starts to rise as UI is raised also shows that UI is achieving little here in terms of consumption smoothing. Instead, the main gain in utility as UI is increased comes from decreases in work disutility. On the other hand, it is also reasonable to claim that this model overstates equilibrium consumption insurance relative to the US economy. Unemployment is higher than intended, reflecting relatively low search activity, even though hiring is higher than our target level of $1 \%$ of output. Also, the consumption innovation due to job loss is lower than the $7 \%$ loss documented by Gruber (1994). Although asset holdings (not reported here) are similar to US levels, the fact that this model considers unemployment risk only, ignoring health risk and uncertainty about the length of life, may mean that asset holdings here represent more effective insurance than pertains in reality. For these three reasons, our model may understate the consumption smoothing importance of UI.

\section{Tax incidence and wage bargaining}

The baseline model described in the previous section assumed that firms paid the taxes financing UI and social security benefits. Here, we will recalculate the model under the assumption that it is the workers, instead, who pay the taxes financing benefits. This is a natural issue to explore since social security taxes, for instance, are deducted directly from worker's paychecks in the U.S. However, it is far from obvious that this distinction should matter; in standard competitive models, tax incidence has no real effects. Shifting the tax burden from the firm to the worker in such a model typically raises the wage by the exact amount of the shifted tax. Neither the firm nor the worker has any change in disposable income; and since both face exactly the same incentives as before, there is no effect on equilibrium labor supply. If the level of tax were changed, the real costs of employment would change, affecting the equilibrium quantity of labor employed; but tax incidence itself has no impact. 
We now show that, in a search model, tax incidence does have real effects. In the previous section, since tax payments did not depend on whether or not work occurred, they did not enter into the expression for the instantaneous surplus associated with working relative to striking. Attributing share $\beta$ of the surplus to the worker yielded:

$$
\hat{w} * M U-D^{W}=\beta\left(M P L * M U-D^{W}\right)
$$

or equivalently

$$
\hat{w}=\beta M P L+(1-\beta) D^{W} / M U
$$

This also led to the following equation, which we used in our baseline to parameterize $D^{W}$ :

$$
D^{W}=\frac{M U}{1-\beta}(\hat{w}-\beta M P L)
$$

Let us assume instead that the worker pays the taxes; note that we must therefore distinguish in this section between the after-tax wage, which we will write as $\hat{w}$, and the before-tax wage $\hat{w}+\tau$. We continue to assume that taxes are due regardless of whether a strike occurs; the worker's gains are thus $(\hat{w}+\tau) M U-D^{W}$ for each unit of time spent working rather than striking, incorporating the whole before-tax wage $\hat{w}+\tau$. The firm's gains if work occurs are $(M P L-(\hat{w}+\tau)) * M U$ per unit of time. Hence we derive the following wage equation:

$$
(\hat{w}+\tau) * M U-D^{W}=\beta\left(M P L * M U-D^{W}\right)
$$

or equivalently, the after tax wage is

$$
\hat{w}=\beta M P L+(1-\beta) D^{W} / M U-\tau
$$

which implies the following parameterization of $D^{W}$ :

$$
D^{W}=\frac{M U}{1-\beta}(\hat{w}+\tau-\beta M P L)
$$

Conditional on $\beta, M P L, M U$, and $D^{W}$, this bargaining solution implies a lower after-tax wage than that given in our baseline equation (16). The total 
cost per unit of labor faced by the firm is unchanged, while the after-tax wage received by the worker is lower by the amount $\tau$, which means that the worker under this new specification is less willing to search for a job. Since $\tau$ must be fairly large to finance the level of social security in our baseline equilibrium, this alteration of the model is likely to have a big impact on the equilibrium. We also see that, conditional on $M U, \beta, M P L$, and labor's share of income, the parameterization of $D^{W}$ would be higher in this model than it was in our baseline. Labor's share should be equated to $(\hat{w}+\tau) n /\left(A n^{\gamma} k^{1-\gamma}-h\right)$ regardless of tax incidence, since the taxes are used to finance worker benefits; hence the inclusion of $\tau$ in equation (20) implies a higher $D^{W}$. Computing an equilibrium based on this higher $D^{W}$ will also imply that workers are substantially less willing to search for work.

From the preceding discussion, it is probably clear already that not only tax incidence, but also the issue of whether tax must be paid when a strike occurs, is important for deriving our wage equation. Again, this question has no role in a competitive model; strikes cannot have any effect on a model in which, by definition, workers can be costlessly replaced. The assumption that tax liabilities are waived in case of a strike is a reasonable one, clearly applicable to social security taxes, which are a part of the wage bill. Consider, then, the case in which taxes are paid by workers, but liability is waived if a strike occurs. The worker's surplus from working is then the after-tax wage $\hat{w} * M U-D^{W}$, for the worker owes nothing if she strikes, and earns $\hat{w}$ net if she works. The firm's gain from work rather than strike is the marginal product of labor minus the before-tax wage it must pay to the worker, which is $(M P L-(\hat{w}+\tau)) * M U$ in units of utility. Thus the wage equation is:

$$
\hat{w} * M U-D^{W}=\beta\left((M P L-\tau) M U-D^{W}\right)
$$

or equivalently

$$
\hat{w}=\beta(M P L-\tau)+(1-\beta) D^{W} / M P L
$$

with the following parameterization equation:

$$
D^{W}=\frac{M U}{1-\beta}(\hat{w}-\beta(M P L-\tau))
$$


This same set of equations also applies for other tax incidence situations, as long as the tax is not due when strikes occur. That is, if the tax is paid by the firm, but is not due when there is a strike, then the worker's gain from work is $\hat{w} * M U-D^{W}$, and the firm's surplus is $(M P L-(\hat{w}+\tau)) M U$, exactly the same expressions used to derive (21)-(23).

We see that this latest version of the wage equation has implications intermediate between the other two. This specification implies a lower after-tax wage than the baseline (16), though not as low as equation (19), and it implies a higher parameterization of $D^{W}$ than (17), though not as high as (20).

This specification, in which taxes are not due if a strike occurs, is an appealing one for the U.S. economy. The fact that the model is then robust to tax incidence is also attractive. However, it was not chosen as the baseline version of the model for Costain (1997b), because it was found to be difficult to pick parameters that fit this version of the model well. As pointed out above, this version implies a higher parameterization of $D^{W}$, for otherwise it yields an equilibrium with lower labor share. But the high disutility of work $D^{W}$ leads to much lower search effort, especially in the first period after job loss, implying an equilibrium unemployment rate that is too high. Hence, for our baseline, we used instead the specification with taxes paid by firms and invariant to strikes.

\subsection{Results: variable tax case}

In Tables 6 and 7, we report the results of a calculation incorporating a wage based on the assumption that taxes vary with strikes. That is, the model is exactly that used in Section 3, except that the baseline wage equation (16) is replaced with (22). All parameters are the same as their original values reported in Table 3, including the disutility of work $D^{W}$.

Note that the equilibrium after-tax wage in this version of the economy is down around 0.67, as opposed to 0.77 in our baseline model. As expected, hiring incentives are greatly altered by this shift in tax incidence and labor costs. We see in Table 7 that firms are hiring strenously; recruitment costs are 


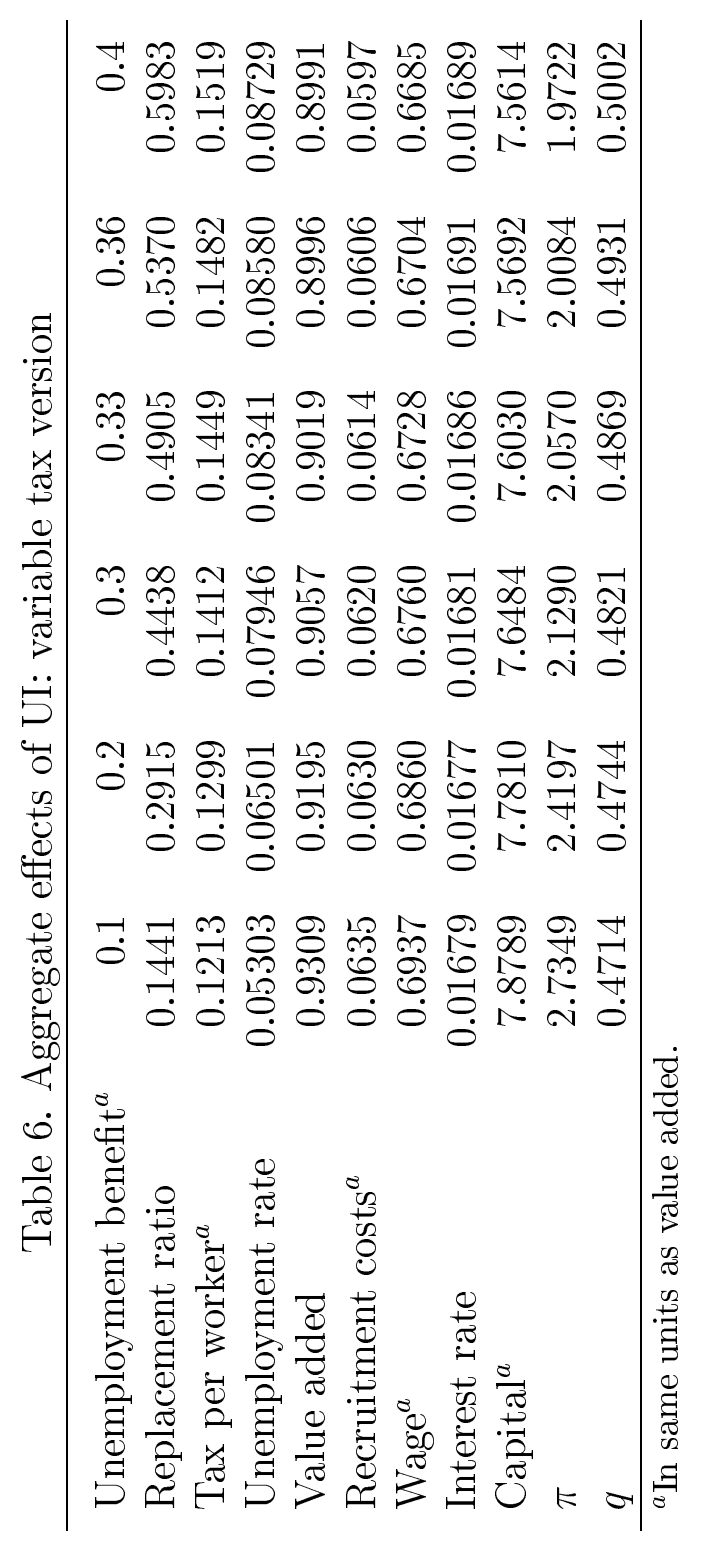




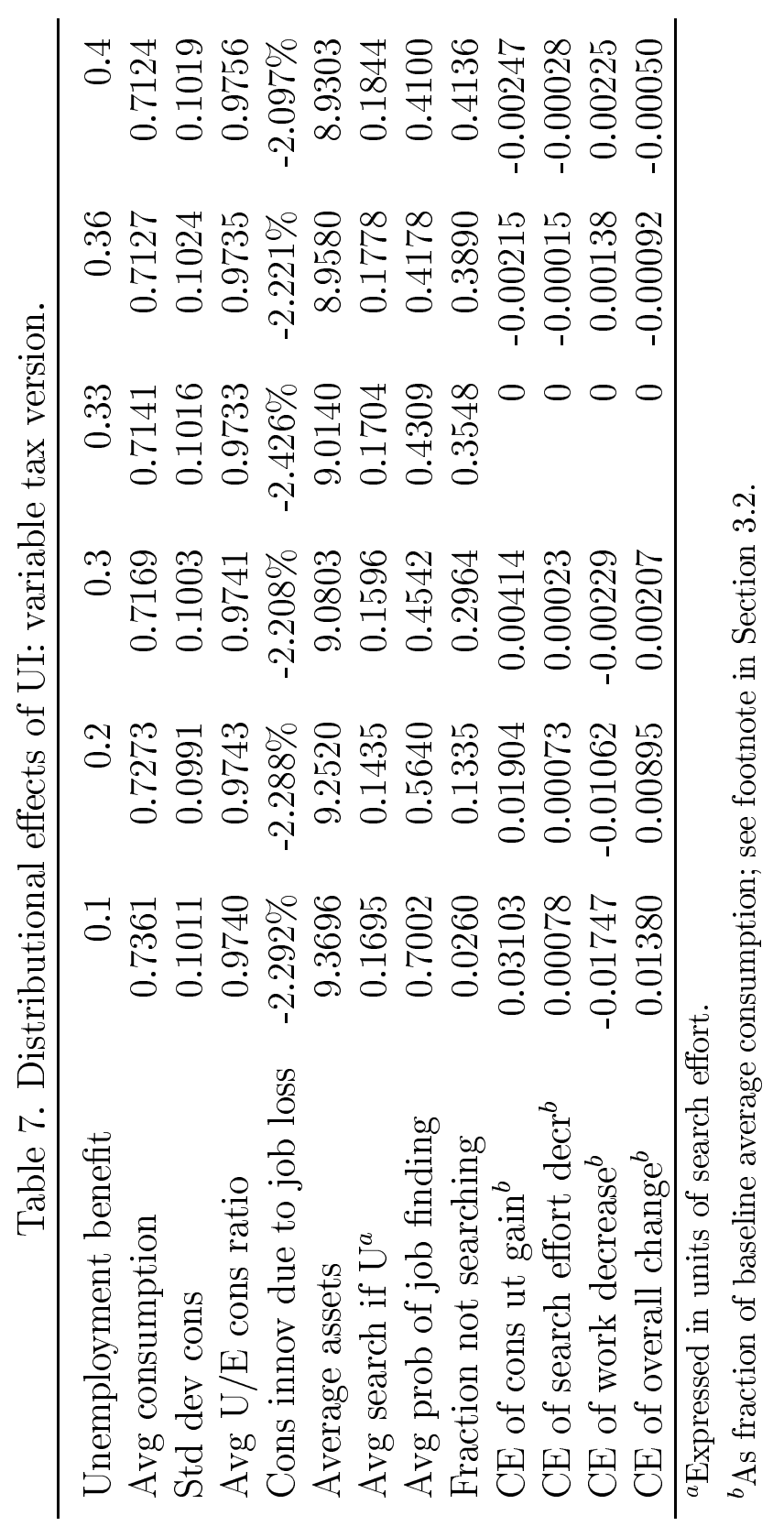


over $6 \%$ of value added, in response to the lower labor costs that firms face in this model. On the other hand, workers are not at all happy about working for these low wages, so we see in the next table that a very large fraction of workers choose not to search at all in their first period of unemployment, except at the lowest replacement ratios. In fact, at $b^{U}=0.33$, almost all workers choose not to search during their first period of unemployment, which guarantees that unemployment will be above $2 \delta=0.08$.

Like the level of unemployment, the rise in unemployment is considerably larger here than in the baseline model; unemployment rises by a full three percent as the UI benefit is raised from 0.1 to 0.33 , as opposed to a $1.7 \%$ rise in the baseline case. Since workers now share in tax incidence, unlike the baseline case, the rise in unemployment is caused more by decreased search activity (especially in the form of zero initial search) rather than decreased hiring. This rise in unemployment is accompanied by a large drop in the capital stock. Value added drops much more than in the baseline, both because of the larger drop in capital and there is little decrease in hiring expenditure to offset falling gross output. Recalling that the benefit of reduced work roughly balanced the loss of consumption due to UI in our baseline, we see in this case that the large loss of consumption hurts workers much more. In fact, utility declines steeply with UI in this version of the model; the certainty equivalent of the loss of consumption utility is roughly twice as large as the certainty equivalent of the decrease in work disutility. Thus, workers would give up $1.38 \%$ of consumption in order to decrease UI from 0.33 to 0.1 .

\section{Monopsonistic wage bargaining}

In this section, we take into account the fact that a firm's investment and hiring change the marginal product of labor at that firm, so that, under bilateral bargaining, the wage is changed. While this effect should be recognized by the firm when it chooses investment and hiring, this has often been neglected. Most papers in the matching literature treat all hirings as bilateral events between a single worker and a single "vacancy", thus avoiding the possibility 
of interactions between the wage bargains of different workers; moreover, the wage is typically taken as given in deriving the first-order condition on investment. In such a model, Pissarides (1990,Ch.2), shows the equivalence of the one-on-one matching framework with an economy allowing for larger firms. On the other hand, Stole and Zwiebel (1996a,b) argue that hiring additional workers should drive down the wages of all workers at a firm, and they solve a complicated multi-agent bargaining problem which incorporates a monopsony feature of this sort. Bertola and Caballero (1994) also treat dynamic labor accumulation in an economy where the firm recognizes the effects of investment and hiring on the wage of all its employees.

Without taking sides in this theoretical debate, we ask here whether it has quantitative importance by comparing the model from Section 3, which ignored interactions between wage bargains, with an alternative in which the firm anticipates wage changes when it alters hiring or investment. Again we must point out that this is an issue which does not arise in traditional competitive models. In a model where there are no search or matching costs, a firm would indeed recognize its power on wages if it were the only local purchaser of labor, or one of a few. However, with frictional labor markets, the size and capital intensity of the firm could affect wages even with many firms in the market, for it is the ex-post bilateral surplus which causes the effects considered here, not the actual number of firms in the market. Equivalently, as long as outside options do not bind, it is the marginal product of labor at a given firm that matters for wage formation, not the marginal product of labor in the economy as a whole.

The firm's first-order conditions, in monopsonistic case, are:

$$
\begin{gathered}
R-\exp (-\delta)=q\left(A \gamma n_{t}{ }^{\gamma-1} k_{t}{ }^{1-\gamma}-w-n_{t} \frac{\partial w}{\partial n}\left(n_{t}, k_{t}\right)-\tau\right) \\
R-\exp \left(-\delta_{k}\right)=A(1-\gamma) n_{t}{ }^{\gamma} k_{t}^{\gamma}-n_{t} \frac{\partial w}{\partial k}\left(n_{t}, k_{t}\right)
\end{gathered}
$$

Making use of our baseline wage equation (14), the partial derivative terms in the firm's necessary conditions become

$$
n_{t} \frac{\partial w}{\partial n}\left(n_{t}, k_{t}\right)=\beta A \gamma(\gamma-1) n_{t}^{\gamma-1} k_{t}^{1-\gamma}
$$




$$
n_{t} \frac{\partial w}{\partial k}\left(n_{t}, k_{t}\right)=\beta A \gamma(1-\gamma) n_{t}^{\gamma} k_{t}^{-\gamma}
$$

Now both of the first-order conditions imply a higher labor-to-capital ratio than the baseline model. The wage depends positively on the marginal product of labor at the firm, which declines as the firm hires more, or as it invests less; hence there is greater hiring and/or decreased investment, as compared with the baseline model.

\subsection{Results: monopsony case}

A simulation allowing for these monopsony effects is reported in Tables 8 and 9. The model is exactly the same as that in Section 3, except for the firm's first-order conditions, and the baseline parameters are used.

This economy shares interesting similarities and differences with the one from the previous section. Once again, it has low wages, lots of hiring, and many workers who prefer not to search at all as long as they are covered by UI. Hiring is almost $10 \%$ of value added when $b^{U}=0.1$, though it declines quickly as the UI benefit is increased. There is also an extremely low capital stock, only about $60 \%$ of the level observed in our other simulations. The resulting low wages, and the ease of finding a job quickly, give workers a great incentive not to search in their first period of UI eligibility; hence again we have an unemployment rate slightly above $8 \%$. Clearly, all these observations are compatible with the monopsonistic incentive we have been discussing.

Although this equilibrium appears somewhat similar to the variable-tax version analyzed in the last section, its response to UI could not be more different. The tendency to overhire because of monopsony incentives amounts to a very powerful negative externality among firms. As UI is increased, hiring expenditure falls substantially, but this is beneficial since there was too much hiring to start with. In fact, we observe a large increase in the capitallabor ratio as the UI benefit is increased, actually leading to a rise in output. Unsurprisingly, this has an extremely positive welfare impact; the optimal replacement ratio appears from our calculations to be well over $100 \%{ }^{7}$ In going

\footnotetext{
${ }^{7}$ Obviously, though, we should not assume that our model is well-suited to studying an economy with a replacement ratio over $100 \%$.
} 
from $b=0.33$ to $b=0.7$, the capital stock rises slightly, from 4.26 to 4.37 , and value added rises even more than recruitment costs fall. Meanwhile, the worker gains consumption utility worth almost $3 \%$ of value added, and decreases work disutility by $0.2 \%$; she suffers only from increased search effort due to higher unemployment.

It is also interesting to note that the change in consumption from increased UI is initially negative, for a rise in UI produces a much larger increase in unemployment when $b^{U}$ is low than when it is high. We see from Table 9 that the reason for the initial sharp rise in unemployment is that many workers choose not to search in their first period of unemployment, once the UI benefit rises above approximately 0.3. After this initial adjustment, most workers appear to leave their search behavior mostly unchanged, for the fraction not searching and the probability of job finding when unemployed remain approximately the same above $b^{U}=0.4$.

\section{The threat point: strike versus separation}

\subsection{The outside option principle in a matching model}

Up to this point, we have employed a Nash bargaining solution, assuming that the worker and the firm each receive fixed shares of match surplus, defined relative to the threat point of a strike. However, the relevant threat points are a matter of debate in the literature. To help explain the alternatives under debate, we will make reference to the Rubinstein alternating offers formulation of the bargaining game, since it is this game that is usually seen as providing the strategic underpinnings of the Nash split and of the appropriate threat points.

The baseline specification used in this paper and in Costain (1997b) is what we have called the "strike threat" wage. ${ }^{8}$ It is most easily explained by considering a period-by-period formulation, in which each period's wage is determined by playing an alternating offers bargaining game at the start of the

\footnotetext{
${ }^{8} \mathrm{~A}$ wage formulation of this sort was first used in Shaked and Sutton (1984).
} 


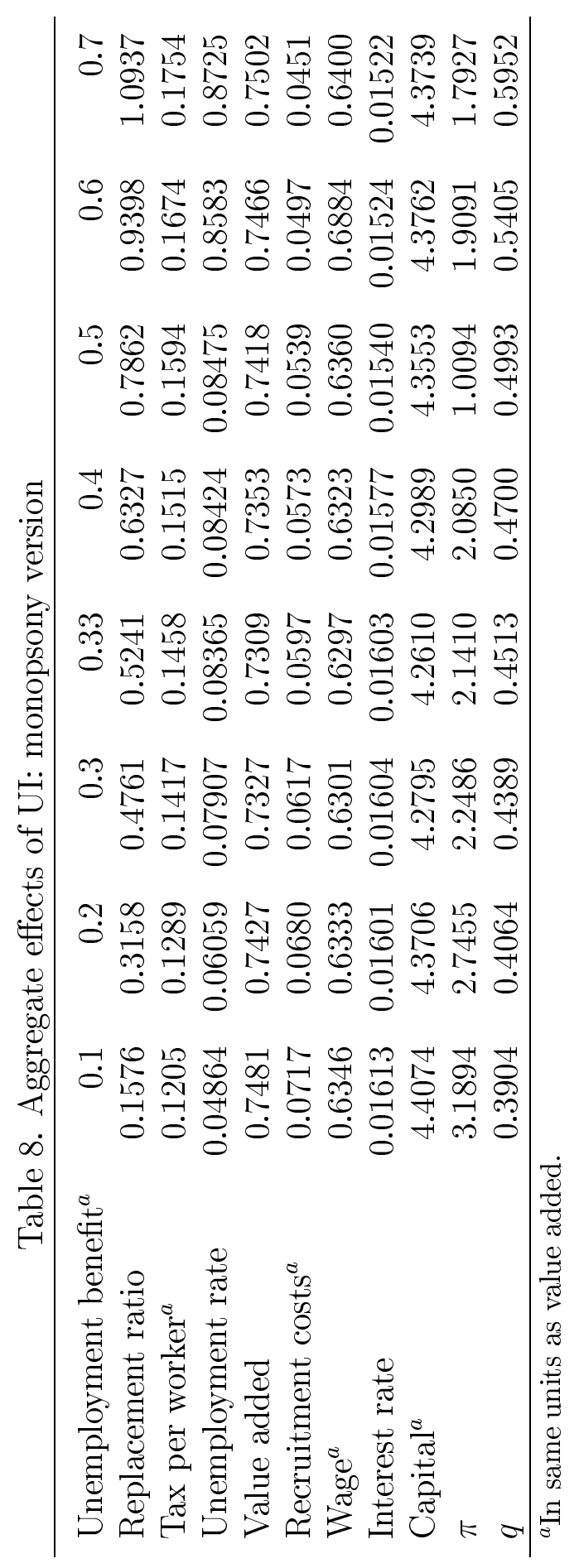




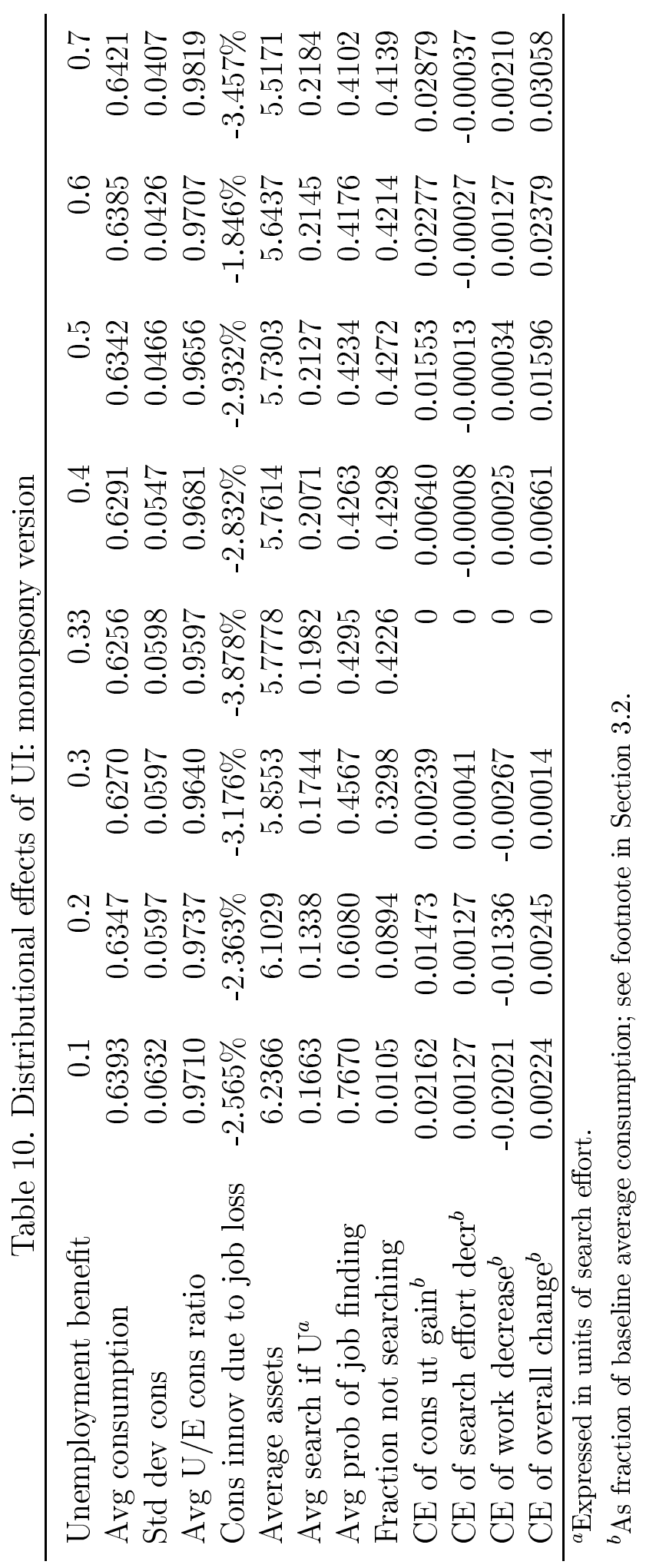


period. If a wage is agreed upon during the bargaining game, then work occurs, so the payoff which accrues to the worker and the firm during the period is $M P L * M U-D^{W}{ }^{9}$ If no wage is agreed upon, there is nonetheless no credible reason for either party to leave the match: each player would decrease her expected future utility by separating. No output would be produced, and no disutility incurred, since the worker is not willing to work except in exchange for a wage payment, so that period's payoff is zero. ${ }^{10}$ Attributing share $\beta$ of that period's surplus to the worker yields the strike threat wage equation:

$$
w * M U-D^{W}=\beta\left(M P L * M U-D^{W}\right)
$$

The alternative "quit threat" wage which is more common in the general equilibrium matching literature is more easily described in intertemporal terms. ${ }^{11}$ Let $V^{W}$ and $V^{F}$ be the equilibrium present discounted utilities of a worker and a firm when they are currently matched; let $U^{W}$ and $U^{F}$ be their present discounted utilities when unmatched. The quit threat bargaining equation then simply states that the worker's increment in intertemporal welfare upon matching is fraction $\beta$ of the total increment in intertemporal welfare:

$$
V^{W}-U^{W}=\beta\left(V^{W}-U^{W}+V^{F}-U^{F}\right)
$$

By writing the present discounted utilities of the agents in terms of the wage, it will be possible to derive an expression for the wage from (29).

\footnotetext{
${ }^{9}$ Lifetime utility, of course, also includes a continuation payoff for future periods, but we need not take it into account in the argument which follows.

${ }^{10}$ The subtle point which is being glossed over in this description of the game is that we are assuming probability zero of arrival of an alternative match opportunity during the strike. However, this is in fact reasonable in an endogenous search equilibrium.

${ }^{11}$ Although we state the strike threat derivation in terms of a bargaining game over one period's wage, and the quit threat derivation in terms of a bargaining game over a wage for the whole lifetime of the match, Costain (1996) demonstrates that the chosen timing has no impact on the distinction between the two bargaining solutions. Each solution can be derived under either time framework, but the quit threat wage arises as a subgame perfect equilibrium only if search intensity is exogenous and is equally effective for unemployed and matched individuals.
} 
One might assume that the Nash split stated in (29) could be derived from an alternating offers game played at the initial moment of matching. The subtle point which complicates this conjecture, however, is the fact that at no point in the bargaining process is it a credible threat to separate, or even to expend disutility searching for an outside offer: hence it is hard to see how $U^{W}$ and $U^{F}$ could possibly enter into the equation as threat points.

Rubinstein and Wolinsky (1985) show that the quit threat wage equation can be derived as the subgame perfect equilibrium of an alternative offers game, but only under a very restrictive assumption: the rate of arrival of new match partners is exogenously fixed, and is the same for the unemployed and for those who are already matched. Wolinsky (1987) examines the case of endogenous search intensity and finds a subgame perfect equilibrium which, in the context of this paper, where all matches are identical, leads to the solution (28) which we have called the strike threat wage. ${ }^{12}$ The intuition behind the fact that the strike threat wage is unrelated to the value of separation in an endogenous search model is very simple: at all times during the bargaining process, workers and firms expect immediate acceptance of the equilibrium (strike threat) wage; hence, since all matches are identical, there is never any incentive for agents to expend disutility on search effort once they have found one potential partner; hence outside offers which could motivate separation never arrive.

Rubinstein and Wolinsky (1985) and Wolinsky (1987) are both applications of the "outside option principle" derived in Binmore, Rubinstein, and Wolinsky (1986), which allows us to restate the distinction between the two results somewhat more formally. Let us ignore the exogenous separation rate $\delta$ of our model and instead assume that matches, once formed, last until at least one party chooses to separate, for $\delta$ plays no role in our argument. Let $E^{W}$ and $E^{F}$ be the equilibrium payoffs arising from the bargaining game for the worker and the firm; since we are assuming no exogenous separation, these payoffs are simply $E^{W}=\left(w * M U-D^{W}\right) / r=V^{W}$ and $E^{F}=(M P L * M U-w * M U) / r=V^{F}$

\footnotetext{
${ }^{12}$ Costain (1996) independently but belatedly rederives a version of Wolinsky's result.
} 
if the discount rate is $r$. Let $O^{W}$ and $O^{F}$ be the "outside options" of the worker and the firm if they become unmatched, which in a search market are $O^{W}=U^{W}$ and $O^{F}=U^{F}$. Finally, Binmore et. al. also define $B^{W}$ and $B^{F}$ as the discounted payoffs which would accrue to the worker and the firm in a hypothetical non-equilibrium time path where they continue bargaining inconclusively and neither ever accepts an offer. The principle of Binmore et. al. is that the outside options play no role in the analysis when they are not binding; instead, the points $B^{W}$ and $B^{F}$ enter as threat points. That is, unless $O^{W}>E^{W}$ or $O^{F}>E^{F}$, the solution arising from a subgame perfect equilibrium is

$$
E^{W}-B^{W}=\beta\left(E^{W}-B^{W}+E^{F}-B^{F}\right)
$$

What are the payoffs $B^{W}$ and $B^{F}$ ? This depends on whether or not additional matching opportunities ever arise for the bargaining pair; two extreme cases present themselves. If new matches arrive to the two matched agents, during the bargaining process, at exactly the same rate that they do for unmatched agents, then the two agents, in the hypothetical state of continual non-agreement, have the same expected utility they would have if they were unmatched: $B^{W}=U^{W}$ and $B^{F}=U^{W}$. Hence, as in Rubinstein and Wolinsky (1986), if search intensity is exogenously fixed and leads to the same rate of new match formation for the unemployed and for those already matched, then the Binmore et. al. bargaining solution (30) is

$$
V^{W}-U^{W}=\beta\left(V^{W}-U^{W}+V^{F}-U^{F}\right)
$$

which is the quit threat wage equation. On the other hand, if no output is produced, no disutility is received, and there is no probability of new match arrivals during the state of continual non-agreement, then the payoff of this state is just $B^{W}=B^{F}=0$. The Binmore et. al. bargaining solution then becomes

$\frac{w * M U-D^{W}}{r}-0=\beta\left(\frac{M P L * M U-w * M U}{r}-0+\frac{w * M U-D^{W}}{r}-0\right)$

which with trivial simplification becomes the strike threat wage equation. 


\subsection{Deriving the quit threat wage}

To compute the quit threat version of the model, we still need to derive an explicit wage equation from (29). We will again simplify our derivation by assuming a constant level of marginal utility, rather than allowing match surplus to vary with asset holdings. In order to solve for the wage, we need to distinguish between the value of employment and the values of unemployment in the first, second, and later periods of an unemployment spell, since these periods have different UI eligibilities. If we call these values $W^{E}, W^{U 1}, W^{U 2}$, and $W^{U 3}$, respectively, then the relevant Bellman equations are: ${ }^{13}$

$$
\begin{gathered}
W^{E}=w M U-D^{W}+\frac{1}{R}\left[\exp (-\delta) W^{E}+(1-\exp (-\delta)) W^{U 1}\right] \\
W^{U 1}=b^{U} M U-D^{S} \bar{s}_{1}+\frac{1}{R}\left[\left(1-\exp \left(-\pi \bar{s}_{1}^{Z}\right)\right) W^{E}+\exp \left(-\pi \bar{s}_{1}^{Z}\right) W^{U 2}\right] \\
W^{U 2}=b^{U} M U-D^{S} \bar{s}_{2}+\frac{1}{R}\left[\left(1-\exp \left(-\pi \bar{s}_{2}^{Z}\right)\right) W^{E}+\exp \left(-\pi \bar{s}_{2}^{Z}\right) W^{U 3}\right] \\
W^{U 3}=-D^{S} \bar{s}_{2}+\frac{1}{R}\left[\left(1-\exp \left(-\pi \bar{s}_{2}^{Z}\right)\right) W^{E}+\exp \left(-\pi \bar{s}_{2}^{Z}\right) W^{U 3}\right]
\end{gathered}
$$

From the firm's problem, in Section 2.1, we can see that the steady state value of the marginal worker at the firm is

$$
\frac{\partial V(n, k)}{\partial n}=\left(\frac{R}{R-e^{-\delta}}\right)[M P L-w-\tau]
$$

The relevant match surplus is then $W^{E}-W^{U 1}+\frac{\partial V(n, k)}{\partial n}$. We assume the worker receives fraction $\beta$ of this surplus, and then perform plenty of tedious algebra, to derive the following wage equation:

$w=\frac{(1-\beta)\left(R-e^{-\delta}\right)}{C_{1}}\left[\left(1+\exp \left(-\pi \bar{s}_{1}^{Z}\right) b^{U}+\left(\left(1+C_{0}\right) D^{W}-D^{S}\left(\bar{s}_{1}+C_{0} \bar{s}_{2}\right)\right) / M U\right]\right.$

\footnotetext{
${ }^{13}$ In order to derive these functions without mention of asset holdings, we must not only ignore variation in marginal utility across individuals, but also ignore variation in search intensity across individuals in the same period of an unemployment spell. Hence we base our calculations on $\bar{s}_{1}$ and $\bar{s}_{2}$, the average levels of search, in equilibrium, in the first and later periods of unemployment, respectively.
} 


$$
\begin{gathered}
+\frac{\beta\left(R+\left(1-e^{-\delta}\right)\left(1+C_{0}\right)\right)}{C_{1}}(M P L-\tau) \\
\text { where } C_{0} \equiv \frac{\exp \left(-\pi \bar{s}_{1}^{Z}\right)}{1-\exp \left(-\pi \bar{s}_{2}^{Z}\right)} \\
\text { and } C_{1} \equiv\left(R-e^{\delta}\right)(1-\beta)\left(1+C_{0}\right)+\beta\left[R+\left(1-e^{-\delta}\right)\left(1+C_{0}\right)\right]
\end{gathered}
$$

This wage equation is of the form

$$
B_{1} * M P L+B_{2} * D^{W} / M U-B_{3} \tau+B_{4} b^{U}-B_{5} * D^{S} / M U
$$

The first two terms of this expression appear comparable to the strike threat wage equation (14). In fact, it is easy to show that $B_{1}$ and $B_{2}$ sum to one, and that they satisfy $B_{1}>\beta$ and $B_{2}<1-\beta$. Thus, the first two terms of (32) are a reweighting of the two components of the strike threat wage, increasing the weight on the larger component $M P L$, which is 0.9443 in our baseline equilibrium, and decreasing the weight on the smaller component $D^{W} / M U=0.5905$. The three remaining terms are all much smaller and approximately cancel each other out. ${ }^{14}$ Hence under reasonable parameters we conclude that the quit threat wage will be somewhat higher than the strike threat wage, for given $M P L$ and $D^{W} / M U$.

\subsection{Results: quit threat case}

As expected, the wage has risen in this equilibrium relative to our baseline model. The wage rise is not as dramatic as the wage decreases in our previous two wage specification experiments, but it nonetheless has a substantial impact on the equilibrium. With the higher wage, we observe few unemployed workers choosing not to search; only $1.3 \%$ set search effort equal to zero, even at $b^{U}=0.5$. Firms, on the other hand, cut back drastically on hiring, relative to the baseline model; recruitment costs are well under $1 \%$ of value added, except at the lowest level of UI. This leads to a high level of equilibrium unemployment, $9.696 \%$ at $b^{U}=0.33$.

\footnotetext{
${ }^{14}$ Note, very roughly, that $\tau \approx \delta b^{U}$, while $B_{4} \approx \delta B_{3}$.
} 
Other aspects of this model, such as its interest rate and capital stock, behave quite similarly to the baseline. The strikingly large effect of the wage decrease thus suggests a closer look at the external effects linking the search and hiring choices of firms and workers. Note that in general, the effects of $\pi$ on search and of $q$ on hiring are ambiguous, as they imply welfare and substitution effects which work in opposite directions. However, it is possible to show numerically for the baseline version of the model that partial equilibrium increases in $\pi$ and $q$ lead to declines in search and hiring (when we hold fixed investment), respectively. ${ }^{15}$ Together, these facts imply strong effects from a fall in $w$ : this raises hiring and lowers search, causing $q$ to fall and $\pi$ to rise, which then implies a further increase in hiring and a further decrease in search.

Again, we find a sharp contrast in the effects of UI, relative to our other models. Since unemployment is high, an increase in UI requires a large rise in taxes, which causes large changes in unemployment and in average consumption. Raising UI from 0.1 to 0.5 leads to a $4.210 \%$ rise in unemployment, as opposed to a $3.509 \%$ rise in the baseline case, and average consumption drops by $0.7727-0.7465=0.0262$ units, almost twice the change observed in the baseline model. With lower hiring here than in the baseline, the rise in unemployment is concentrated in decreased search, rather than decreased hiring. Thus decreased hiring yields little offsetting effect on the fall in gross output, explaining why the falls in value added and in consumption are so much larger than in the baseline. Also, at the high level of unemployment observed here, the rise in UI and unemployment leads to a much larger cost in terms of increased search disutility than in the baseline case. Overall, then, the utility impact of UI is very negative. Raising UI from 0.1 to 0.33 has a total utility impact equivalent to a loss of almost $1 \%$ of baseline average consumption, while raising it from 0.33 to 0.5 amounts to another loss of over $1 \%$ of baseline average consumption.

\footnotetext{
${ }^{15}$ Evaluated at our baseline equilibrium, the elasticity of average search with respect to $\pi$ is -0.8384 . Holding fixed the choice of investment, the elasticity of hiring with respect to $q$ is -0.8826 . Note that these partial equilibrium responses are equally applicable to either wage model.
} 


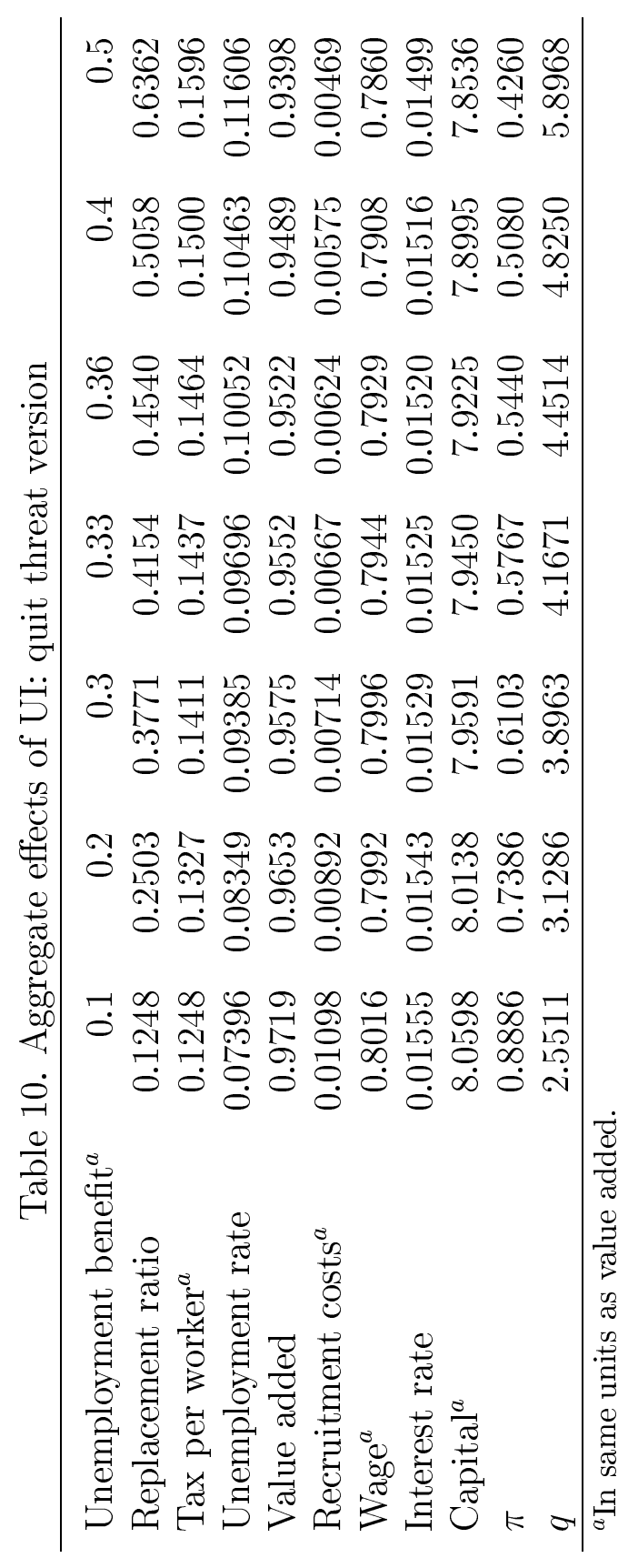




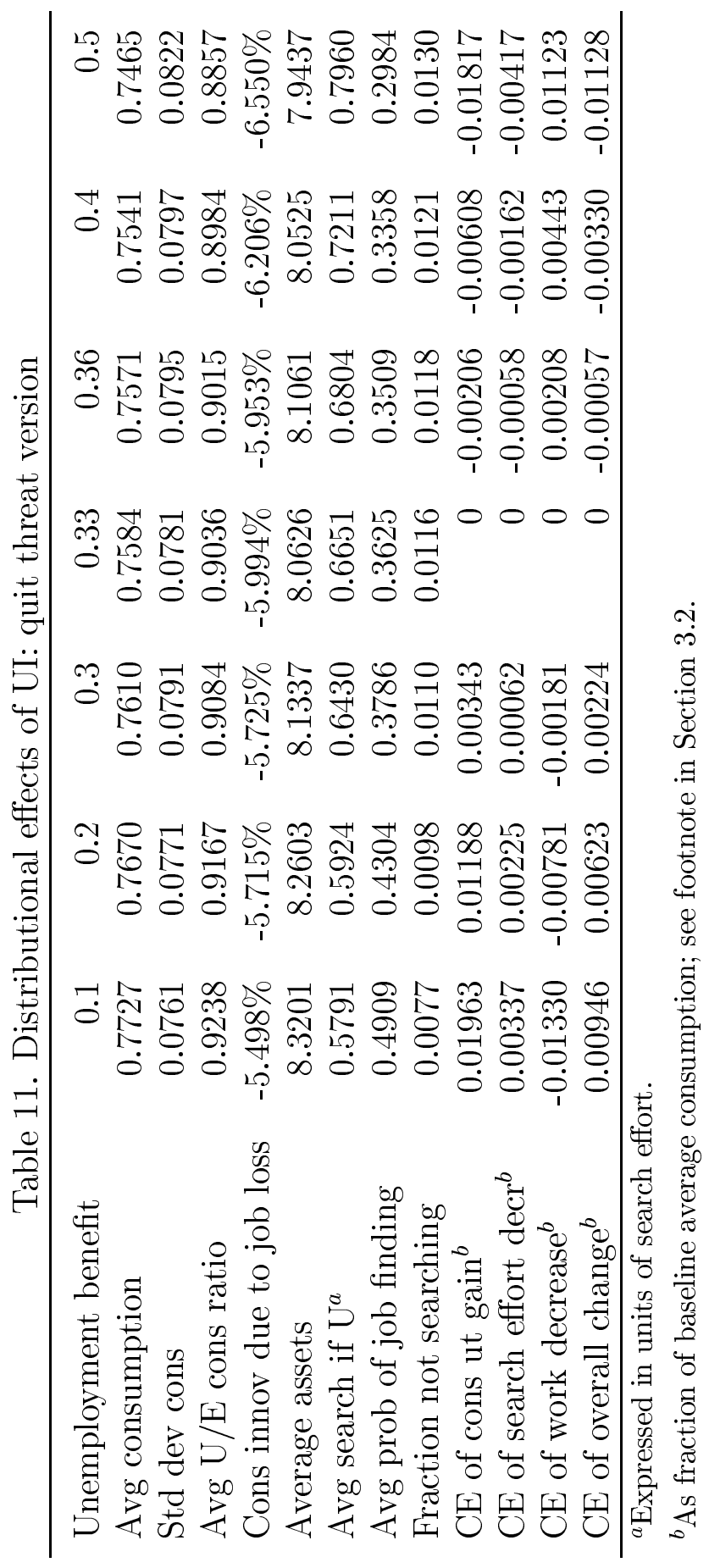




\section{Conclusions}

In this paper, we have simulated four general equilibrium matching models. All the models are based on the same parameterization, in a nested framework which is intended to provide a quantitative analysis of the effects of unemployment insurance for the US economy. The models differ only in terms of rather subtle changes in the wage equation, drawn from theoretical debates regarding the appropriate specification of wage bargaining. These changes in the wage equation are shown to have large effects on unemployment and on other aspects of the equilibrium. Since the welfare analysis of UI depends on the net impact of several offsetting effects, the optimal replacement ratio changes radically as the wage equation is changed. The importance of the wage equation appears especially large when compared to the consumption smoothing benefits of UI, which are negligible in this log utility model, though they become somewhat larger in more risk averse simulations reported in Costain (1997b).

Imposing more realistic tax incidence on the model, namely a tax which is waived if a strike occurs, or a tax which is partly incident on the worker, leads to a higher parameterization of the disutility of work, and/or a lower equilibrium wage. Both these effects greatly discourage job search, and lead to an equilibrium with high unemployment in which UI is very harmful.

Allowing for monopsony power on the part of firms, so that hiring additional workers is anticipated to drive down the wage bargaining outcome with other workers, leads to a substantial incentive for over-hiring. Like the previous experiment, this implies an equilibrium in which hiring is relatively high, and search relatively low. However, in this case the elevated level of hiring is so inefficient that lowering it by raising UI has a very positive welfare impact.

Finally, the quit threat wage is somewhat higher than the strike threat wage, and thus has less of a tendency to promote overhiring. With the quit threat wage, equilibrium search effort is high, while hiring expenditure is low, and raising UI has very negative implications for welfare.

Several further generalizations can be made about our results. First, as discussed in Section 6.3, our model shows considerable sensitivity to the wage, 
based on the externalities which result from the negative effects of $\pi$ on search effort and of $q$ on hiring expenditure. Second, our welfare analyses appear to depend strongly on the relative quantities of hiring and search effort that go into match formation. UI is most beneficial where it leads to relatively large decreases in hiring, rather than in search activity - namely, the baseline and monopsony cases. Though we have not attempted to derive an efficiency criterion along the lines of Hosios (1990) for this complicated model, the contrasting welfare analyses suggest that our baseline equilibrium features somwhat too much hiring and not enough search. The effects of tax incidence also feed through this mechanism, because the two versions which place part of tax incidence on the workers - the variable tax case and the quit threat case - have larger declines in search activity rather than in hiring as UI is raised.

Taken together, these calculations provide an important reminder of the fragility of policy analysis models. They also remind us that non-competitive economies incorporate many profound externalities. They invite empirical work on wage setting, though the subtle wage interactions analyzed here do not promise easy empirical analysis.

\section{REFERENCES}

Bertola, Giuseppe, and Ricardo J. Caballero (1994), "Cross-Sectional Efficiency and Labour Hoarding in a Matching Model of Unemployment." R.E.S. 61 (3), pp. 435-57.

Binmore, Ken, Ariel Rubinstein, and Asher Wolinsky (1986), "The Nash Bargaining Solution in Economic Modelling." Rand Journal of Economics 17 (2), pp. 176-88.

Blanchard, Olivier, and Peter Diamond (1989), "The Beveridge Curve." Brookings Pap. Econ. Activity 0 (1) pp. 1-60.

Costain, James S. (1995), "General Equilibrium Unemployment Insurance: The Exponential Utility Case." Manuscript.

Costain, James S. (1996), "A Note on Wage Bargaining in Matching Models." Manuscript.

Costain, James S. (1997a), "Unemployment Insurance in a General Equilibrium Model of Job Search and Precautionary Saving." Dissertation, Univ. of Chicago. 
Costain, James S. (1997b), "Unemployment Insurance with Endogenous Search Intensity and Precautionary Saving." Univ. Pompeu Fabra Working Paper 243.

Engen, Eric M., and Jonathan Gruber (1995), "Unemployment Insurance and Precautionary Saving." Manuscript.

Gruber, Jonathan (1997), "The Consumption Smoothing Benefits of Unemployment Insurance." A.E.R. 87 (1) pp. 192-205.

Hosios, Arthur J. (1990), "On the Efficiency of Matching and Related Models of Search and Unemployment." R.E.S. 57 (2), pp. 279-298.

Meyer, Bruce D. (1990), "Unemployment Insurance and Unemployment Spells." Econometrica 58 (4) pp. 757-82.

Meyer, Bruce D. (1995), "Lessons from the U.S. Unemployment Insurance Experiments." J.E.L. 33 (1) pp. 91-131.

Pissarides, Christopher A. Equilibrium Unemployment Theory. Cambridge, Mass.: Blackwell. 1990.

Rubinstein, Ariel (1982), "Perfect Equilibrium in a Bargaining Model. Econometrica 50 (1) pp. 97-109.

Rubinstein, Ariel, and Asher Wolinsky (1985), "Equilibrium in a Market with Sequential Bargaining." Econometrica 53 (5), pp. 1133-50.

Shaked, Avner, and John Sutton (1984), "Involuntary Unemployment as a Perfect Equilibrium in a Bargaining Model." Econometrica 52 (6), pp. 1351-64.

Solon, Gary (1985), "Work Incentive Effects of Taxing Unemployment Benefits." Econometrica 53 (2) pp. 295-306.

Stole, Lars A., and Jeffrey Zwiebel (1996a), "Organizational Design and Technology Choice under Intrafirm Bargaining." A.E.R. 86 (1) pp. 195-222.

Stole, Lars A., and Jeffrey Zwiebel (1996b), "Intra-firm Bargaining under Nonbinding Contracts." R.E.S. 63 (3) pp. 375-410.

Wolinsky, Asher (1987), "Matching, Search, and Bargaining." Journal of Economic Theory 42 (2), pp. 311-33. 